2020-12

Survived but not safe: Marine heatwave hinders metabolism in two gastropod survivors

\title{
Hemraj, DA
}

http://hdl.handle.net/10026.1/16257

\subsection{6/j.marenvres.2020.105117 \\ Marine Environmental Research \\ Elsevier BV}

All content in PEARL is protected by copyright law. Author manuscripts are made available in accordance with publisher policies. Please cite only the published version using the details provided on the item record or document. In the absence of an open licence (e.g. Creative Commons), permissions for further reuse of content should be sought from the publisher or author. 
This is a final draft of the submitted paper. Please refer to the published version of this paper: Hemraj, D.A., Posnett, N.C., Minuti, J.J., Firth, L.B. and Russell, B.D., 2020. Survived but not safe: Marine heatwave hinders metabolism in two gastropod survivors. Marine Environmental Research, p.105117 https://doi.org/10.1016/j.marenvres.2020.105117

Survived but not safe: marine heatwave hinders metabolism in two gastropod survivors

Deevesh A. Hemraj ${ }^{1}$, Natasha C. Posnett ${ }^{2}$, Jay J. Minuti ${ }^{1}$, Louise B. Firth ${ }^{3}$, Bayden D. Russell ${ }^{{ }^{*}}$

PL4 8AA, UK

*corresponding author: brussell@hku.hk 
This is a final draft of the submitted paper. Please refer to the published version of this paper: Hemraj, D.A., Posnett, N.C., Minuti, J.J., Firth, L.B. and Russell, B.D., 2020. Survived but not safe: Marine heatwave hinders metabolism in two gastropod survivors. Marine Environmental Research, p.105117 https://doi.org/10.1016/j.marenvres.2020.105117

Graphical abstract

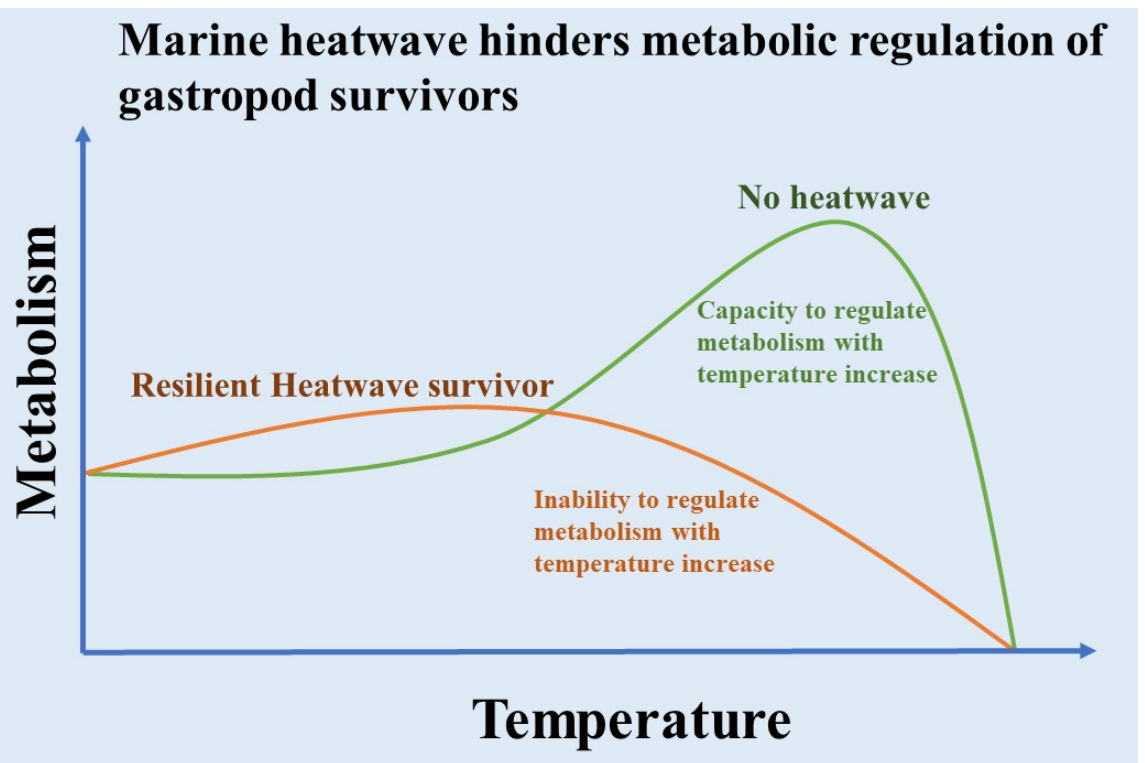


This is a final draft of the submitted paper. Please refer to the published version of this paper: Hemraj, D.A., Posnett, N.C., Minuti, J.J., Firth, L.B. and Russell, B.D., 2020. Survived but not safe: Marine heatwave hinders metabolism in two gastropod survivors. Marine Environmental Research, p.105117 https://doi.org/10.1016/j.marenvres.2020.105117

\section{Abstract}

42 Marine heatwaves (MHWs) are an emerging threat to marine organisms that have increased in frequency and magnitude in the past decade. These extreme heating events can have differential impacts for organisms with some experiencing mortality while others survive. Here, we experimentally exposed two species of subtidal gastropod (Trochus sacellum and Astralium haematragum) to two realistic intensities of MHW to test the ability of different species to physiologically cope with extreme heating events. Extreme MHW conditions caused 100\% mortality in both species within five days. In contrast, both species showed evidence of nonadaptive metabolic depression under moderate MHW conditions. Both species demonstrated an inability to upregulate their metabolic rates at the higher temperatures following exposure to a MHW (i.e. reduced temperature of maximum metabolic rate; $\mathrm{T}_{\mathrm{MMR}}$ ), suggesting a lack of molecular protective responses and ongoing physiological damage. Therefore, the physiological damage endured by heatwave survivors may lessen their ability to cope with subsequent stress until fully recovered. Repairing this damage may have serious 
This is a final draft of the submitted paper. Please refer to the published version of this paper: Hemraj, D.A., Posnett, N.C., Minuti, J.J., Firth, L.B. and Russell, B.D., 2020. Survived but not safe: Marine heatwave hinders metabolism in two gastropod survivors. Marine Environmental Research, p.105117 https://doi.org/10.1016/j.marenvres.2020.105117

\section{Introduction}

Marine heatwaves (MHWs) are recognised as major threats to biodiversity because they drive mass mortality of organisms (Garrabou et al., 2009; Le Nohaïc et al., 2017), changes in species geographical distribution (Wernberg et al., 2016; Lonhart et al., 2019; Sanford et al., 2019), and re-organisation of community composition (Arafeh-Dalmau et al., 2019; Brodeur et al., 2019). The overarching effect of MHWs on biodiversity is dependent not only on the duration and magnitude of thermal stress but also on the sensitivity of the organisms themselves (Frölicher and Laufkötter, 2018; Leung et al., 2019). Since tolerance to thermal stress is associated with the ability to regulate aerobic capacity and maintain physiological homeostasis (Madeira, 2018 a), interspecific discrepancies in the effects of MHWs exist whereby some species are resistant or resilient, while others are sensitive (Leung et al, 2019). Thus, some species can be categorised as 'winners' for exhibiting adaptive phenotypic plasticity in response to MHWs (Cavole et al., 2016; Watson, 2018) while others will be 'losers' when they are unable to tolerate acute warming and die.

While different magnitudes of heat stress from MHWs can be lethal for some species, the activation of physiological pathways associated with aerobic metabolism and cellular stress response allow others to be resistant or resilient to thermal stress (Leung et al., 2019). Speciesspecific regulation of physiological mechanisms to cope with stress under heatwaves are present even among species from the same habitat (Bernal et al., 2020). Additionally, the metabolic pathways that are activated to tolerate or survive thermal stress, such as cellular 
This is a final draft of the submitted paper. Please refer to the published version of this paper: Hemraj, D.A., Posnett, N.C., Minuti, J.J., Firth, L.B. and Russell, B.D., 2020. Survived but not safe: Marine heatwave hinders metabolism in two gastropod survivors. Marine Environmental Research, p.105117 https://doi.org/10.1016/j.marenvres.2020.105117

metabolism, cholesterol metabolism, or activation of the complement system (a component of immune response), will differ among surviving species (Bernal et al., 2020). However, the regulation of molecular mechanisms is energetically costly and, consequently, increases in thermal tolerance come with the requirement of balancing responses with energy reserves and enhancement in energy intake and assimilation following the heat stress (Giomi et al., 2016; Leung et al., 2019).

The capacity of an organism to physiologically adjust in response to fluctuating environmental temperatures depends largely on their natural realised thermal windows, and whether they are able to both display thermally compensated respiratory functions, as well as extend their lethal temperature thresholds (Sandblom et al., 2016). Depending on the duration and magnitude of a heatwave, the thermotolerance strategy employed by a species, the associated energetic costs, and the ability of different species to regulate metabolism and energy assimilation after a MHW will lead to different physiological consequences during and post-MHW. It is generally accepted that sensitivity of an organism to environmental change and capacity for thermal acclimation is determined by environmental selection pressure, which is often correlated with latitude although a wider suite of selective pressures may concurrently be involved (Jupe et al., 2020). Generally, species living in more stable tropical environments have greater capacity for chronic thermal acclimation when the rate of onset is slower, whereas those which live in more thermally variable environments are more equipped to deal with acute temperature change through physiological plasticity given the range experienced in their natural environment (Seebacher et al., 2015). Indeed, predicting the different responses of more tropical and temperate-affiliated species in areas in which their ranges overlap is complex, due to variety in thermotolerance mechanisms utilised by functionally similar species (Goldenberg et al., 2018). 
This is a final draft of the submitted paper. Please refer to the published version of this paper: Hemraj, D.A., Posnett, N.C., Minuti, J.J., Firth, L.B. and Russell, B.D., 2020. Survived but not safe: Marine heatwave hinders metabolism in two gastropod survivors. Marine Environmental Research, p.105117 https://doi.org/10.1016/j.marenvres.2020.105117

An understanding of these responses is of increasing importance for predicting how warming seas will drive species range shifts and novel biological communities (Donelson et al., 2019; Sanford et al., 2019; Wernberg et al., 2016).

Here, we investigated the effect of different magnitudes of realistic MHW scenarios (moderate and extreme; Hobday et al., 2018) on the metabolism and survival of two subtidal gastropods, Trochus sacellum and Astralium haematragum, which co-occur in a tropical-temperate transition zone. T. sacellum is widely distributed in tropical and temperate waters between Korea and the Philippines (Batomalaque et al., 2010; Noseworthy and Kwang-Sik, 2010) while A. haematragum is distributed mainly around the cooler waters of Japan (Meyer et al., 2005) and Korea (Noseworthy and Kwang-Sik, 2010), reaching its southern trailing edge near Hong Kong. Both T. sacellum and A. haematragum are common subtidal grazers in Hong Kong, where they are exposed to substantial seasonal fluctuations in water temperature. Here, we investigate the capacity of these species with different geographic distributions, and therefore evolutionary thermal histories, to regulate their metabolism during heatwave scenarios. We then examine possible interspecific differences in the capacity to regulate metabolism post MHW. We hypothesised that the magnitude of MHW will drive the metabolic rate and survival of gastropods whereby the more tropical species (T. sacellum) will demonstrate greater survival and ability to regulate metabolism under moderate heatwave conditions because of its evolutionary history under warmer temperatures, but both species will have elevated mortality under extreme heatwave conditions (i.e. inability to acclimate). Secondly, we hypothesised that the capacity of gastropods to regulate their aerobic metabolism immediately following heatwaves will be impaired because of the heatwave induced physiological damage. We predict this reduced function will be more prominent in the more tropical species ( T. sacellum) because 
This is a final draft of the submitted paper. Please refer to the published version of this paper: Hemraj, D.A., Posnett, N.C., Minuti, J.J., Firth, L.B. and Russell, B.D., 2020. Survived but not safe: Marine heatwave hinders metabolism in two gastropod survivors. Marine Environmental Research, p.105117 https://doi.org/10.1016/j.marenvres.2020.105117

while tropical species are thought to live closer to their upper thermal limits, the stable conditions mean they have a smaller thermal safety margin and are more likely to endure high physiological damage under subsequent stress, possibly leading to death. The physiological state of these organisms post-MHW will have large repercussions for their ability to maintain grazing, their key functional role in the ecosystem. Therefore, unravelling the consequences of MHWs on their physiological state is key to understanding their ability for enduring environmental stress, to recover, and to maintain their ecological function post MHW.

\section{Methods}

\subsection{Organism collection}

Individuals of Trochus sacellum and Astralium haematragum were collected from the subtidal waters of Bluff island, Hong Kong $\left(22^{\circ} 19^{\prime} 18.0^{\prime \prime} \mathrm{N} 114^{\circ} 21^{\prime} 18.2^{\prime \prime} \mathrm{E}\right)$, by SCUBA diving, in summer so that they were seasonally acclimated to warm summer conditions. Organisms were brought to the laboratory and allowed to acclimate to laboratory conditions for a period of 24 hours at $28^{\circ} \mathrm{C}$ (ambient water temperature during collection) in aquaria fitted with an open flow-through system providing clean filtered seawater to acclimate to laboratory conditions.

\subsection{Experiment 1: MHW simulation}

To start the heatwave treatment, replicate aquaria $(12 \mathrm{~L})$ were maintained at $28^{\circ} \mathrm{C}$ (ambient control), or gradually increased to $31^{\circ} \mathrm{C}$ (moderate heatwave) or $34^{\circ} \mathrm{C}$ (extreme heatwave) ( $\mathrm{n}=3$ aquaria per treatment, $\mathrm{n}=6$ individuals per aquarium) over 24 hours using flow-through systems to pump pre-heated water into experimental aquaria. These temperatures were chosen to elucidate current summer conditions (control: Fig. 1) and predicted future heatwave conditions under climate change. Temperatures were then maintained for seven days using 
This is a final draft of the submitted paper. Please refer to the published version of this paper: Hemraj, D.A., Posnett, N.C., Minuti, J.J., Firth, L.B. and Russell, B.D., 2020. Survived but not safe: Marine heatwave hinders metabolism in two gastropod survivors. Marine Environmental Research, p.105117 https://doi.org/10.1016/j.marenvres.2020.105117

flow-through heater/chiller units (Hailea, Model HC.2200BH) and water temperature was monitored twice daily. Daily checks were made to record any mortality and dead individuals were removed and not replaced. After the 7-day heatwave treatments, metabolic rates of organisms were measured at treatment conditions (see "Metabolic rate" below) before temperatures were gradually reduced back to $28^{\circ} \mathrm{C}$ over 24 hours. Following the 24-hour recovery, all individuals were used in thermal ramps (see below). Gastropods were fed ad libitum with filamentous turf-algae naturally growing on rocks collected from field for the duration of the experiment.

\subsection{Metabolic rate}

Metabolic rates of individuals were measured both prior to exposure to (i.e. all at $28{ }^{\circ} \mathrm{C}$ ) and after the seven days of heatwave exposure (i.e., at $28^{\circ} \mathrm{C}, 31^{\circ} \mathrm{C}$, or $34^{\circ} \mathrm{C}$ ). Metabolism was measured as change in oxygen concentration in sealed air-tight glass respirometry chambers containing an oxygen sensor spot (PreSens SP-PSt3-YAU). Chambers were placed into a large water bath at experimental temperature to maintain temperature constant throughout measurements, with a magnetic stirrer in each chamber used to ensure water was thoroughly mixed throughout measurements. One individual organism was placed into each chamber which was sealed under water ensuring that no air bubbles were present. Organisms were allowed to rest for five minutes, after which oxygen concentrations were measured every five minutes for 30 minutes using a fibre optic meter (Firebox 4 Trace). For each temperature treatment, one blank chamber with no gastropod was used to measure change in oxygen concentration and to take into account any biological activity in the water. Ten individuals per temperature treatment were selected randomly for the respiration measurements $(n=10)$. Final 
This is a final draft of the submitted paper. Please refer to the published version of this paper: Hemraj, D.A., Posnett, N.C., Minuti, J.J., Firth, L.B. and Russell, B.D., 2020. Survived but not safe: Marine heatwave hinders metabolism in two gastropod survivors. Marine Environmental Research, p.105117 https://doi.org/10.1016/j.marenvres.2020.105117

metabolic rate was calculated as the rate of oxygen concentration depletion in seawater as a function of body weight and time $\left(\mathrm{mgO}_{2} \mathrm{~L}^{-1} \mathrm{gfw}^{-1} \mathrm{~h}^{-1}\right)$.

\subsection{Experiment 2: Analysis of post MWH physiology through thermal ramps}

Following the 24-hour recovery after heatwave exposure, metabolic rates of six individuals from each exposure type (control or heatwave) were measured $(n=6)$ on a thermal ramp following the same procedure as for metabolic rate measurements. Prior to commencement of the thermal ramp, individuals were housed in aquaria in which the temperature had been reduced to $16^{\circ} \mathrm{C}$ over 24 hours. Thermal ramps had an initial temperature of $16^{\circ} \mathrm{C}$ (with a ramping rate of $2^{\circ} \mathrm{C}$ every two hours until mortality, with metabolic rate measured at every $2^{\circ} \mathrm{C}$ interval. Thermal ramps started at $16{ }^{\circ} \mathrm{C}$ because it represents the winter temperature experienced by the organisms and was used to cover their full natural temperature range (Fig. 1). Mortality was used as the end point to assess whether acclimation to experimental treatments allowed individuals to increase the temperature of mortality (upper lethal limit: ULL). Prior to measuring oxygen consumption, the organisms were allowed to acclimate at each temperature for one hour, after which the respirometry chambers were sealed and oxygen concentration in the chambers were measured every five minutes for 20 minutes. Water temperature was regulated using heater/chillers (Hailea, Model HC.2200BH).

\subsection{Data analysis}

To test for the effect of heatwaves (control vs. moderate heatwave) on respiration a one-way permutational analysis of variance (PERMANOVA) was done using Euclidean distance $(\mathrm{n}=10)$ using Primer 7 + PERMANOVA. Exponentially Modified Gaussian Function (EMG) models were fitted for temperature ramp data as per Angilletta (2006) to extract the temperature 
This is a final draft of the submitted paper. Please refer to the published version of this paper: Hemraj, D.A., Posnett, N.C., Minuti, J.J., Firth, L.B. and Russell, B.D., 2020. Survived but not safe: Marine heatwave hinders metabolism in two gastropod survivors. Marine Environmental Research, p.105117 https://doi.org/10.1016/j.marenvres.2020.105117

at maximum metabolic rate ( $\left.\mathrm{T}_{\mathrm{MMR}}\right)$, upper lethal limit (ULL), and to model the change in metabolic rate over the temperature ramp for both species pre- and post-heatwave exposure. An EMG was performed for the thermal ramp dataset from each group independently, based the mean and variances within each dataset. EMGs were modelled using RStudio Version 1.1.463.

\section{Results}

\subsection{Mortality}

Mortality of organisms exposed to the extreme heatwave $\left(34^{\circ} \mathrm{C}\right)$ was higher than those from the moderate heatwave $\left(31^{\circ} \mathrm{C}\right.$; Fig. 2). Exposure to extreme heatwave conditions caused 100 $\%$ mortality after three days for $T$. sacellum and five days for A. haematragum. Moderate heatwave conditions $\left(31^{\circ} \mathrm{C}\right)$, caused the same level of mortality for both species, but mortality was delayed for A. haematragum; $17 \%$ of $T$. sacellum individuals died after four days followed by no further deaths while $17 \%$ of $A$. haematragum died after six of exposure. There was no mortality at current summer temperatures (control; $28^{\circ} \mathrm{C}$ ).

\subsection{Metabolic rates}

As extreme heatwave conditions caused $100 \%$ mortality, metabolic rates were only obtained for organisms exposed to moderate heatwave and control summer conditions. Contrary to predictions, elevated temperature $\left(31^{\circ} \mathrm{C}\right)$ did not cause a rise in metabolic rate of the individuals which survived the moderate heatwave for both T. sacellum and A. haematragum (Fig. 3, all $\mathrm{p}>0.1)$

\subsection{Thermal ramps}


This is a final draft of the submitted paper. Please refer to the published version of this paper: Hemraj, D.A., Posnett, N.C., Minuti, J.J., Firth, L.B. and Russell, B.D., 2020. Survived but not safe: Marine heatwave hinders metabolism in two gastropod survivors. Marine Environmental Research, p.105117 https://doi.org/10.1016/j.marenvres.2020.105117

Exposure to moderate heatwave conditions caused a change in metabolic rates across thermal ramps for both $T$. sacellum and A. haematragum compared to individuals kept at control summer temperatures. Metabolism of T. sacellum exposed to control conditions $\left(28^{\circ} \mathrm{C}\right)$ remained low between $16^{\circ} \mathrm{C}$ to $28^{\circ} \mathrm{C}\left(\mathrm{Q}_{10}=1.73\right)$, then increased four-fold between $28^{\circ} \mathrm{C}$ and $34^{\circ} \mathrm{C}\left(\mathrm{Q}_{10}=14.39\right.$; Fig. 4a) before rapidly declining. In contrast, individuals previously exposed to moderate heatwave conditions $\left(31^{\circ} \mathrm{C}\right)$ displayed nonadaptive metabolic depression (sensu Verberk et al., 2016) across the temperature ramp and did not have an increase in metabolic rates at higher temperatures; metabolism remained low between $16^{\circ} \mathrm{C}$ to $28^{\circ} \mathrm{C}$ $\left(\mathrm{Q}_{10}=1.77\right)$, then decreased between $28^{\circ} \mathrm{C}$ and $34^{\circ} \mathrm{C}\left(\mathrm{Q}_{10}=0.02\right)($ Fig. $4 \mathrm{a})$. Metabolic rates of A. haematragum followed a similar trend $\left(16^{\circ} \mathrm{C}\right.$ to $28^{\circ} \mathrm{C}$ : $\mathrm{Q}_{10}=1.3$ and 0.94 for control and moderate heatwave, respectively; $28^{\circ} \mathrm{C}$ to $34^{\circ} \mathrm{C}$ : $\mathrm{Q}_{10}=21.06$ and 0.08 for control and moderate heatwave, respectively). The $\mathrm{T}_{\mathrm{MMR}}$ for gastropods exposed to control conditions were $32.6^{\circ} \mathrm{C}$ and $35.5^{\circ} \mathrm{C}$ for $T$. sacellum and A. haematragum, respectively. Exposure to moderate heatwave conditions changed the overall metabolic response to temperature across the thermal ramp, reducing the metabolic rates of both species at temperatures above $30^{\circ} \mathrm{C}$ suggesting nonadaptive metabolic depression (Fig. 4, Table 1). The $\mathrm{T}_{\mathrm{MMR}}$ of both the temperate $(A$. haematragum, $\left.-9.8^{\circ} \mathrm{C}\right)$ and the more tropical species $\left(\right.$ T. sacellum, $\left.-4.0^{\circ} \mathrm{C}\right)$ (Table 2) were also reduced following exposure to the moderate heatwave, further suggesting nonadaptive metabolic depression and stress. There was no change in the ULL of either species under the different treatments.

\section{Discussion}

The impact of heatwaves on the physiology and survival of organisms is generally thought to be dependent on their duration and magnitude, and, just as importantly, on the ability of the 
This is a final draft of the submitted paper. Please refer to the published version of this paper: Hemraj, D.A., Posnett, N.C., Minuti, J.J., Firth, L.B. and Russell, B.D., 2020. Survived but not safe: Marine heatwave hinders metabolism in two gastropod survivors. Marine Environmental Research, p.105117 https://doi.org/10.1016/j.marenvres.2020.105117

species to cope with thermal stress (Frölicher and Laufkötter 2018). Physiologically coping with thermal stress is, in turn, dependent on factors including the ability to maintain homeostasis of metabolic systems (Sokolova et al., 2012; Giomi et al., 2016; Leung et al., 2019). Yet, the efficacy of coping mechanisms vary among even functionally similar species within the same habitat (Bernal et al., 2020). Here, we show that the magnitude of MHW indeed influenced the survival of two subtidal marine species with different distributions and evolutionary histories, whereby neither species were able to survive under extreme heatwave conditions $\left(+6^{\circ} \mathrm{C}\right.$ above summer temperatures) but only experienced $17 \%$ mortality under the moderate heatwave scenario $\left(+3^{\circ} \mathrm{C}\right.$ above summer temperatures). There was, however, a difference in the onset of mortality between species with the more tropical $T$. sacellum succumbing to thermal stress more rapidly in both extreme and moderate heatwave scenarios than the more temperate $A$. haematragum. Theory suggests that thermal tolerance is linked to species geographical distribution (Bozinovic et al., 2011; Seebacher et al., 2014), where more tropical-affinity species experience more stable environments and have narrow thermal windows, while temperate species posess the ability to maintain broader thermal windows because they are adapted to greater environmental variation (Stillman and Somero, 2000). We found that our tropical species experienced maximum metabolic rate at a lower temperature ( $\left.\mathrm{T}_{\mathrm{MMR}}\right)$ than the temperate species, which when surpassed, drove the more rapid onset of mortality. Indeed, tropical species are generally thought to live close to their upper thermal limits and have a reduced thermal safety margin (Bozinovic et al., 2011). Correspondingly, the consistently higher mortality rate of $T$. sacellum observed across both heatwave magnitudes suggests that it possesses lower capability to withstand high temperatures compared to $A$. haematragum. 
This is a final draft of the submitted paper. Please refer to the published version of this paper: Hemraj, D.A., Posnett, N.C., Minuti, J.J., Firth, L.B. and Russell, B.D., 2020. Survived but not safe: Marine heatwave hinders metabolism in two gastropod survivors. Marine Environmental Research, p.105117 https://doi.org/10.1016/j.marenvres.2020.105117

Contrary to what is expected under metabolic theory, the metabolic rates of $T$. sacellum and A. haematragum exposed to moderate MHW were not different to metabolic rates under normal summer temperatures. While this could be interpreted as both species acclimating to moderate MHW conditions (sensu Seebacher et al. 2015), metabolic acclimation is unlikely over the 7-day heatwave. In contrast, the post-MHW thermal ramps revealed that exposure to MHWs impeded the capacity of both species to maintain aerobic metabolism at higher temperatures (i.e. nonadaptive metabolic depression), likely driven by thermal stress (Verberk et al., 2016). The inability of both species to increase aerobic metabolism at temperatures above $30^{\circ} \mathrm{C}$ in line with individuals from the natural summer conditions $\left(28^{\circ} \mathrm{C}\right)$, suggests that both species were undergoing nonadaptive metabolic depression to reduce energetic costs (Jacobson et al., 2016). Comparable effects have also been observed in the gastropod Thalotia conica (Leung et al., 2017) and crustaceans Rhynchocinetes durbanensis and Calcinus laevimanus (Madeira et al, 2018b) where although organisms survived thermal stress, they were unable to maintain higher respiration at elevated temperatures and their physiological state was severely impacted. Therefore, although $T$. sacellum and A. haematragum were able to survive the moderate MHW over the shorter term, the physiological costs likely rendered them unable to sustain additional thermal stress because of the increased energetic requirements.

The observed nonadaptive metabolic depression post-MHW likely results from one of two possible mechanisms. Firstly, the immediate response of thermal stress involves the disruption of systemic oxygen balance (Pörtner, 2001; Pörtner and Knust, 2007; Kassahn et al., 2009), neccesiting increased mitochondrial capacity, or activation of a complementary system to restore normal function (Bernal et al., 2020; Kassahn et al., 2009; Sokolova et al, 2012). These compensatory mechanisms increase energy demands which may lead to severe depletion in 
This is a final draft of the submitted paper. Please refer to the published version of this paper: Hemraj, D.A., Posnett, N.C., Minuti, J.J., Firth, L.B. and Russell, B.D., 2020. Survived but not safe: Marine heatwave hinders metabolism in two gastropod survivors. Marine Environmental Research, p.105117 https://doi.org/10.1016/j.marenvres.2020.105117

energy reserves (Ganser et al, 2015; Leung et al., 2017; Madeira et al, 2018a). Consequently, following a MHW, surviving individuals may be physiologically impaired, including depleted energy reserves and reduced cellular function (e.g. Madeira et al., 2018b). Such organisms would have a drasticaly reduced capacity to regulate metabolic rates under further stress. Secondly, at the edge of thermal tolerance, compensatory mechanisms may be insuficient to maintain aerobic function and a switch to anaerobic function, reducing availability and supply of cellular energy (Kassahn et al., 2009). Such metabolic switches cause cellular damage, impaired mitochondrial function, and reduced oxygen delivery capacity (Dimitriadis et al., 2012; Leung et al., 2017). While this strategy can limit metabolic costs and enhance short-term survival, it is a maladaptive strategy and reduces the ability of organisms to maintain adequate metabolic function under further stress, until partially or fully recovered.

We hypothesised that the capacity of the more tropical species (T. sacellum) to tolerate heatwaves would be less than the temperate species given the history of stable conditions rather than acute temperature change. A recent meta-analysis of the upper temperature limits of 34 tropical ectotherms found that under rapid warming the upper lethal temperature range for subtidal organisms (more thermally stable, similar to $T$. sacellum) was between $37-41^{\circ} \mathrm{C}$ but between $41-52^{\circ} \mathrm{C}$ for intertidal organisms (more thermally variable, similar to $A$. haematragum) (Nguyen et al, 2011). As T. sacellum has a more tropical affinity, and therefore evolved under more stable environmental conditions in its realised niche, it may have physiological processes acclimated to tolerate the more stable tropical subtidal conditions and hence experienced high mortality in response to rapid thermal stress. While less than $20 \%$ of individuals died under the moderate heatwave scenario, longer, or repeated heatwaves could reduce subsequent generations to the point where shifts in invertebrate assemblages occur 
This is a final draft of the submitted paper. Please refer to the published version of this paper: Hemraj, D.A., Posnett, N.C., Minuti, J.J., Firth, L.B. and Russell, B.D., 2020. Survived but not safe: Marine heatwave hinders metabolism in two gastropod survivors. Marine Environmental Research, p.105117 https://doi.org/10.1016/j.marenvres.2020.105117

(Smale et al, 2017), weakening or eliminating their ability to perform their ecological functions and cascading to more drastic community- or ecosystem-wide changes (Brodeur et al., 2019; Smale et al, 2017; Wernberg et al, 2013).

Even subtle environmental changes can cause vast shifts within communities, due to intraspecific variation within different populations of a given species (Harley et al., 2017; Wang et al., 2018). In our study, those individuals which did survive the moderate MWH (of both species) were rendered incapable of regulating their metabolic rates at high temperatures. Whilst their resting metabolic rate did not change, the maximum temperature theshold limits showed little flexibility to increase (indeed, declined markedly), which ultimately reduced survivability and resulted in a less succesful thermal response strategy (Armstrong et al., 2019). These species, therefore, demonstrate resilience rather than resistance to moderate MHWs (Leung et al., 2019), meaning that they rely on recovering from thermal stress rather than coping with it and maintaining function. Under such circumstances, the required recovery period post MHW can play a crucial role in the future survival of both species, which would also be dependent on the type of physiological damage incurred during the MHW. The inability to physiologically resist acute heating events has caused extensive range contractions of temperate species, even through singular acute thermal events. For example, the 2015/2016 heatwave in southeast Australia saw sea surface temperatures $+3-4^{\circ} \mathrm{C}$ above climatological averages, and observations of numerous fish and invertebrate species were found out of range in Tasman waters (Oliver et al., 2017; Caputi., 2014). This heatwave caused a rapid climate driven regime shift, losing the temperate defining kelp forests which were replaced by tropical and subtropical associated species, a community wide tropicalisation event (Wernberg et al., 2016). Therefore, the period of exposure to thermal stress, sustained physiological damage and recovery period, and periodicity of recurring MHWs can determine the overlying impact on 
This is a final draft of the submitted paper. Please refer to the published version of this paper: Hemraj, D.A., Posnett, N.C., Minuti, J.J., Firth, L.B. and Russell, B.D., 2020. Survived but not safe: Marine heatwave hinders metabolism in two gastropod survivors. Marine Environmental Research, p.105117 https://doi.org/10.1016/j.marenvres.2020.105117

populations and the wider community (Arias-Ortiz et al., 2018; Madeira et al., 2018b). With the number of MHW days expected to continue increasing over the coming decades (Oliver et al., 2018), and with differences in the adaptive phenotypic plasticity of species with overlapping distributions (Cavole et al., 2016; Watson, 2018), the success in fully recovering from MHW exposure lies at the core of the ability of species to survive, recover, and resume their ecological functions post-MHW.

\section{Acknowledgements}

We thank the staff of the Swire Institute of Marine Science for helping to maintain the experimental systems. This project was funded by a Hong Kong Research Grants Council General Research Fund grant (GRF17122916) to and a Universitas 21 Fellowship BDR.

\section{References}

1. Angilletta Jr, M. J. 2006. Estimating and comparing thermal performance curves. Journal of Thermal Biology 31(7):541-545.

2. Arafeh-Dalmau, N., G. Montaño-Moctezuma, J. A. Martinez, R. Beas-Luna, D. S. Schoeman, and G. Torres-Moye. 2019. Extreme Marine Heatwaves alter kelp forest community near its equatorward distribution limit. Frontiers in Marine Science 6:499.

3. Arias-Ortiz, A., O. Serrano, P. Masqué, P. S. Lavery, U. Mueller, G. A. Kendrick, M. Rozaimi, A. Esteban, J. W. Fourqurean, and N. Marbà. 2018. A marine heatwave drives massive losses from the world's largest seagrass carbon stocks. Nature Climate Change 8(4):338.

4. Armstrong, E. J., R. L. Tanner, and J. H. Stillman. 2019. High Heat Tolerance Is Negatively Correlated with Heat Tolerance Plasticity in Nudibranch Mollusks. Physiological and Biochemical Zoology 92(4):430-444. 
This is a final draft of the submitted paper. Please refer to the published version of this paper: Hemraj, D.A., Posnett, N.C., Minuti, J.J., Firth, L.B. and Russell, B.D., 2020. Survived but not safe: Marine heatwave hinders metabolism in two gastropod survivors. Marine Environmental Research, p.105117 https://doi.org/10.1016/j.marenvres.2020.105117

5. Batomalaque, G. A., B. G. P. Arce, M. B. M. Hernandez, and I. K. C. Fontanilla. 2010. Survey and spatial distribution of shoreline malacofauna in Grande Island, Subic Bay. Philippine Journal of Science 139(2):149-159.

6. Bernal, M. A., C. Schunter, R. Lehmann, D. J. Lightfoot, B. J. Allan, H. D. Veilleux, J. L. Rummer, P. L. Munday, and T. Ravasi. 2020. Species-specific molecular responses of wild coral reef fishes during a marine heatwave. Science advances 6(12):eaay3423.

7. Bozinovic, F., P. Calosi, and J. I. Spicer. 2011. Physiological correlates of geographic range in animals. Annual Review of Ecology, Evolution, and Systematics 42:155-179.

8. Brodeur, R. D., T. D. Auth, and A. J. Phillips. 2019. Major shifts in pelagic micronekton and macrozooplankton community structure in an upwelling ecosystem related to an unprecedented marine heatwave. Frontiers in Marine Science

9. Caputi, N., G. Jackson, and A. Pearce. 2014. The marine heat wave off western Australia during the summer of 2010/11: 2 years on. Fisheries Research Division, Western Australian Fisheries and Marine ....

10. Cavole, L. M., A. M. Demko, R. E. Diner, A. Giddings, I. Koester, C. M. Pagniello, M.-L. Paulsen, A. Ramirez-Valdez, S. M. Schwenck, and N. K. Yen. 2016. Biological impacts of the 2013-2015 warm-water anomaly in the Northeast Pacific: Winners, losers, and the future. Oceanography 29(2):273-285.

11. Dimitriadis, V. K., C. Gougoula, A. Anestis, H. O. Pörtner, and B. Michaelidis. 2012. Monitoring the biochemical and cellular responses of marine bivalves during thermal stress by using biomarkers. Marine environmental research 73:70-77.

12. Donelson, J. M., J. M. Sunday, W. F. Figueira, J. D. Gaitán-Espitia, A. J. Hobday, C. R. Johnson, J. M. Leis, S. D. Ling, D. Marshall, and J. M. Pandolfi. 2019.

Understanding interactions between plasticity, adaptation and range shifts in response to marine environmental change. Philosophical Transactions of the Royal Society B 374(1768):20180186.

13. Frölicher, T. L., and C. Laufkötter. 2018. Emerging risks from marine heat waves. Nature communications 9(1):650.

14. Ganser, A. M., T. J. Newton, and R. J. Haro. 2015. Effects of elevated water temperature on physiological responses in adult freshwater mussels. Freshwater Biology 60(8):1705-1716.

15. Garrabou, J., R. Coma, N. Bensoussan, M. Bally, P. Chevaldonné, M. Cigliano, D. Díaz, J.-G. Harmelin, M. C. Gambi, and D. Kersting. 2009. Mass mortality in Northwestern Mediterranean rocky benthic communities: effects of the 2003 heat wave. Global change biology 15(5):1090-1103 .

16. Giomi, F., C. Mandaglio, M. Ganmanee, G.-D. Han, Y.-W. Dong, G. A. Williams, and G. Sarà. 2016. The importance of thermal history: costs and benefits of heat exposure in a tropical, rocky shore oyster. Journal of Experimental Biology 219(5):686-694.

17. Goldenberg, S. U., I. Nagelkerken, E. Marangon, A. Bonnet, C. M. Ferreira, and S. D. Connell. 2018. Ecological complexity buffers the impacts of future climate on marine consumers. Nature Climate Change 8(3):229-233.

18. Harianto, J., H. D. Nguyen, S. P. Holmes, and M. Byrne. 2018. The effect of warming on mortality, metabolic rate, heat-shock protein response and gonad growth in thermally acclimated sea urchins (Heliocidaris erythrogramma). Marine Biology 165(6):96. 
This is a final draft of the submitted paper. Please refer to the published version of this paper: Hemraj, D.A., Posnett, N.C., Minuti, J.J., Firth, L.B. and Russell, B.D., 2020. Survived but not safe: Marine heatwave hinders metabolism in two gastropod survivors. Marine Environmental Research, p.105117 https://doi.org/10.1016/j.marenvres.2020.105117

19. Harley, C. D., S. D. Connell, Z. A. Doubleday, B. Kelaher, B. D. Russell, G. Sarà, and B. Helmuth. 2017. Conceptualizing ecosystem tipping points within a physiological framework. Ecology and evolution 7(15):6035-6045.

20. Jacobson, L. M., P. J. Edmunds, E. B. Muller, and R. M. Nisbet. 2016. The implications of reduced metabolic rate in resource-limited corals. Journal of Experimental Biology 219(6):870-877.

21. Kassahn, K. S., R. H. Crozier, H. O. Pörtner, and M. J. Caley. 2009. Animal performance and stress: responses and tolerance limits at different levels of biological organisation. Biological Reviews 84(2):277-292.

22. Le Nohaïc, M., C. L. Ross, C. E. Cornwall, S. Comeau, R. Lowe, M. T. McCulloch, and V. Schoepf. 2017. Marine heatwave causes unprecedented regional mass bleaching of thermally resistant corals in northwestern Australia. Scientific reports 7(1): 14999.

23. Leung, J. Y., S. D. Connell, and B. D. Russell. 2017. Heatwaves diminish the survival of a subtidal gastropod through reduction in energy budget and depletion of energy reserves. Scientific reports 7(1): 17688 .

24. Leung, J. Y., B. D. Russell, and S. D. Connell. 2019. Adaptive Responses of Marine Gastropods to Heatwaves. One Earth 1(3):374-381.

25. Lonhart, S. I., R. Jeppesen, R. Beas-Luna, J. A. Crooks, and J. Lorda. 2019. Shifts in the distribution and abundance of coastal marine species along the eastern Pacific Ocean during marine heatwaves from 2013 to 2018. Marine Biodiversity Records 12(1):13.

26. Madeira, C., V. Mendonça, A. A. Flores, M. S. Diniz, and C. Vinagre. 2018a. High thermal tolerance does not protect from chronic warming-A multiple end-point approach using a tropical gastropod, Stramonita haemastoma. Ecological indicators 91:626-635.

27. Madeira, C., M. C. Leal, M. S. Diniz, H. N. Cabral, and C. Vinagre. 2018b. Thermal stress and energy metabolism in two circumtropical decapod crustaceans: Responses to acute temperature events. Marine environmental research 141:148-158.

28. Meyer, C. P., J. B. Geller, and G. Paulay. 2005. Fine scale endemism on coral reefs: archipelagic differentiation in turbinid gastropods. Evolution 59(1):113-125.

29. Nguyen, K. D. T., S. A. Morley, C.-H. Lai, M. S. Clark, K. S. Tan, A. E. Bates, and L. S. Peck. 2011. Upper temperature limits of tropical marine ectotherms: global warming implications. PLoS One 6(12)

30. Noseworthy, R. G., and K.-S. Choi. 2010. The diversity and ecology of mollusks in Seogundo off the southern Jeju Island, Republic of Korea. The Korean Journal of Malacology 26(1):19-31.

31. Oliver, E., M. Donat, M. Burrows, P. Moore, D. Smale, L. Alexander, J. Benthuysen, M. Feng, A. Gupta, and A. Hobday. 2018. Longer and more frequent marine heatwaves over the past century Nat. Commun. 9:1324.

32. Oliver, E. C., J. A. Benthuysen, N. L. Bindoff, A. J. Hobday, N. J. Holbrook, C. N. Mundy, and S. E. Perkins-Kirkpatrick. 2017. The unprecedented 2015/16 Tasman Sea marine heatwave. Nature communications $8(1): 1-12$.

33. Sanford, E., J. L. Sones, M. García-Reyes, J. H. Goddard, and J. L. Largier. 2019. Widespread shifts in the coastal biota of northern California during the 2014-2016 marine heatwaves. Scientific reports 9(1):4216. 
This is a final draft of the submitted paper. Please refer to the published version of this paper: Hemraj, D.A., Posnett, N.C., Minuti, J.J., Firth, L.B. and Russell, B.D., 2020. Survived but not safe: Marine heatwave hinders metabolism in two gastropod survivors. Marine Environmental Research, p.105117 https://doi.org/10.1016/j.marenvres.2020.105117

34. Sanford, E., J. L. Sones, M. García-Reyes, J. H. Goddard, and J. L. Largier. 2019. Widespread shifts in the coastal biota of northern California during the 2014-2016 marine heatwaves. Scientific reports 9(1):1-14.

35. Seebacher, F., C. R. White, and C. E. Franklin. 2015. Physiological plasticity increases resilience of ectothermic animals to climate change. Nature Climate Change 5(1):61-66.

36. Smale, D. A., T. Wernberg, and M. A. Vanderklift. 2017. Regional-scale variability in the response of benthic macroinvertebrate assemblages to a marine heatwave. Marine Ecology Progress Series 568:17-30.

37. Sokolova, I. M., M. Frederich, R. Bagwe, G. Lannig, and A. A. Sukhotin. 2012. Energy homeostasis as an integrative tool for assessing limits of environmental stress tolerance in aquatic invertebrates. Marine environmental research 79:1-15.

38. Somero, G. 2010. The physiology of climate change: how potentials for acclimatization and genetic adaptation will determine 'winners' and 'losers'. Journal of Experimental Biology 213(6):912-920.

39. Stillman, J. H., and G. N. Somero. 2000. A comparative analysis of the upper thermal tolerance limits of eastern Pacific porcelain crabs, genus Petrolisthes: influences of latitude, vertical zonation, acclimation, and phylogeny. Physiological and Biochemical Zoology 73(2):200-208.

40. Watson, G. J. 2018. "Winners" and "losers" in the Anthropocene: Understanding adaptation through phenotypic plasticity. Functional Ecology 32(8):1906-1907.

41. Wernberg, T., S. Bennett, R. C. Babcock, T. De Bettignies, K. Cure, M. Depczynski, F. Dufois, J. Fromont, C. J. Fulton, and R. K. Hovey. 2016. Climate-driven regime shift of a temperate marine ecosystem. Science 353(6295):169-172.

42. Wernberg, T., D. A. Smale, F. Tuya, M. S. Thomsen, T. J. Langlois, T. De Bettignies, S. Bennett, and C. S. Rousseaux. 2013. An extreme climatic event alters marine ecosystem structure in a global biodiversity hotspot. Nature Climate Change 3(1):7882. 
This is a final draft of the submitted paper. Please refer to the published version of this paper: Hemraj, D.A., Posnett, N.C., Minuti, J.J., Firth, L.B. and Russell, B.D., 2020. Survived but not safe: Marine heatwave hinders metabolism in two gastropod survivors. Marine Environmental Research, p.105117 https://doi.org/10.1016/j.marenvres.2020.105117

Table 1. The results of repeated measures PERMANOVAs testing for the effect of exposure

to the moderate heatwave (Exposure) on metabolic rates at different temperatures

(Temperature) across thermal ramps for both Trochus sacellum and Astralium haematragum.

515

\begin{tabular}{r|llll}
\multicolumn{2}{c}{ Factor } & Df & F & p-value \\
\hline Trochus sacellum & Exposure & 1 & 3.2839 & 0.085 \\
Respiration rate & Temperature & 11 & 12.948 & $\mathbf{0 . 0 0 1}$ \\
& Individual (Exposure) & 10 & 3.8986 & $\mathbf{0 . 0 0 1}$ \\
& Exposure x Temperature & 11 & 14.046 & $\mathbf{0 . 0 0 1}$ \\
& & & & \\
Astralium haematragum & & & & \\
Respiration rate & Exposure & 1 & 5.8452 & $\mathbf{0 . 0 3}$ \\
& Temperature & 11 & 4.5485 & $\mathbf{0 . 0 0 3}$ \\
& Individual (Exposure) & 9 & 2.2956 & $\mathbf{0 . 0 2 1}$ \\
& Exposure x Temperature & 11 & 6.0839 & $\mathbf{0 . 0 0 1}$
\end{tabular}


This is a final draft of the submitted paper. Please refer to the published version of this paper: Hemraj, D.A., Posnett, N.C., Minuti, J.J., Firth, L.B. and Russell, B.D., 2020. Survived but not safe: Marine heatwave hinders metabolism in two gastropod survivors. Marine Environmental Research, p.105117 https://doi.org/10.1016/j.marenvres.2020.105117

Table 2. Temperature at maximum metabolic rate $\left(\mathrm{T}_{\mathrm{MMR}}\right)$ as described by an Exponentially Modified Gaussian Function (EMG) model for the more tropical Trochus sacellum and more temperate Astralium haematragum after exposure to either summer water $\left(28^{\circ} \mathrm{C}\right)$ or moderate heatwave conditions $\left(31^{\circ} \mathrm{C}\right)$. The difference in $\mathrm{T}_{\mathrm{MMR}}$ in the heatwave compared to the control treatment predicted by the EMG model are also shown.

\begin{tabular}{lccc}
\hline & & $\mathrm{T}_{\mathrm{MMR}}\left({ }^{\circ} \mathrm{C}\right)$ & Change \\
\hline \multirow{3}{*}{ Trochus sacellum } & $28^{\circ} \mathrm{C}$ & 32.6 & $/$ \\
\multirow{4}{*}{ Astralium haematragum } & $31^{\circ} \mathrm{C}$ & 28.6 & $\mathbf{- 4 . 0}$ \\
& $28^{\circ} \mathrm{C}$ & 35.5 & $/$ \\
& $31^{\circ} \mathrm{C}$ & 25.7 & $\mathbf{- 9 . 8}$ \\
\hline
\end{tabular}


This is a final draft of the submitted paper. Please refer to the published version of this paper: Hemraj, D.A., Posnett, N.C., Minuti, J.J., Firth, L.B. and Russell, B.D., 2020. Survived but not safe: Marine heatwave hinders metabolism in two gastropod survivors. Marine Environmental Research, p.105117 https://doi.org/10.1016/j.marenvres.2020.105117

Figure 1: Mean monthly sea water temperature at Bluff Island (Mooring PM11) in Port

Shelter bay, Hong Kong from January 2015 to November 2018. Data downloaded from the Environmental Protection Department, Hong Kong

(https://www.epd.gov.hk/epd/english/environmentinhk/water/hkwqrc/waterquality/marine.ht $\mathrm{ml}$.).

Figure 2: Cumulative mortality (\%) of Trochus sacellum and Astralium haematragum exposed to heatwave of $31^{\circ} \mathrm{C}$ and $34^{\circ} \mathrm{C}$. No mortality was recorded in the control treatment $\left(28^{\circ} \mathrm{C}\right)$.

Figure 3: Metabolic rate of Trochus sacellum and Astralium haematragum at summer water temperatures (control; $\left.28^{\circ} \mathrm{C}\right)$ and following 7 days exposure to either control $\left(28^{\circ} \mathrm{C}\right)$ or moderate heatwave conditions $\left(31^{\circ} \mathrm{C}\right)$. Error bars: $\pm \mathrm{SE}(\mathrm{n}=10)$.

Figure 4: Respiration rates of (a) Trochus sacellum and (b) Astralium haematragum previously exposed to either control summer $\left(28^{\circ} \mathrm{C}\right)$ or moderate heatwave $\left(31^{\circ} \mathrm{C}\right)$ across a thermal ramp. Error bars $\pm \mathrm{SE}(\mathrm{n}=6)$ 
This is a final draft of the submitted paper. Please refer to the published version of this paper: Hemraj, D.A., Posnett, N.C., Minuti, J.J., Firth, L.B. and Russell, B.D., 2020. Survived but not safe: Marine heatwave hinders metabolism in two gastropod survivors. Marine Environmental Research, p.105117 https://doi.org/10.1016/j.marenvres.2020.105117

Figure 1

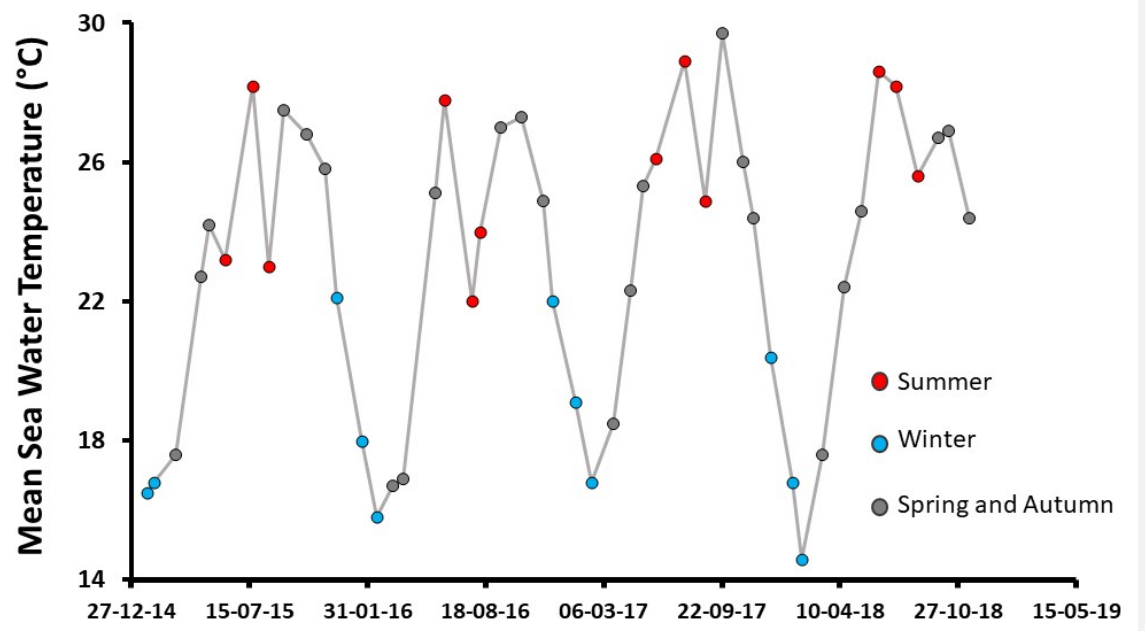

\section{Date}


This is a final draft of the submitted paper. Please refer to the published version of this paper: Hemraj, D.A., Posnett, N.C., Minuti, J.J., Firth, L.B. and Russell, B.D., 2020. Survived but not safe: Marine heatwave hinders metabolism in two gastropod survivors. Marine Environmental Research, p.105117 https://doi.org/10.1016/j.marenvres.2020.105117

560

561

Figure 2

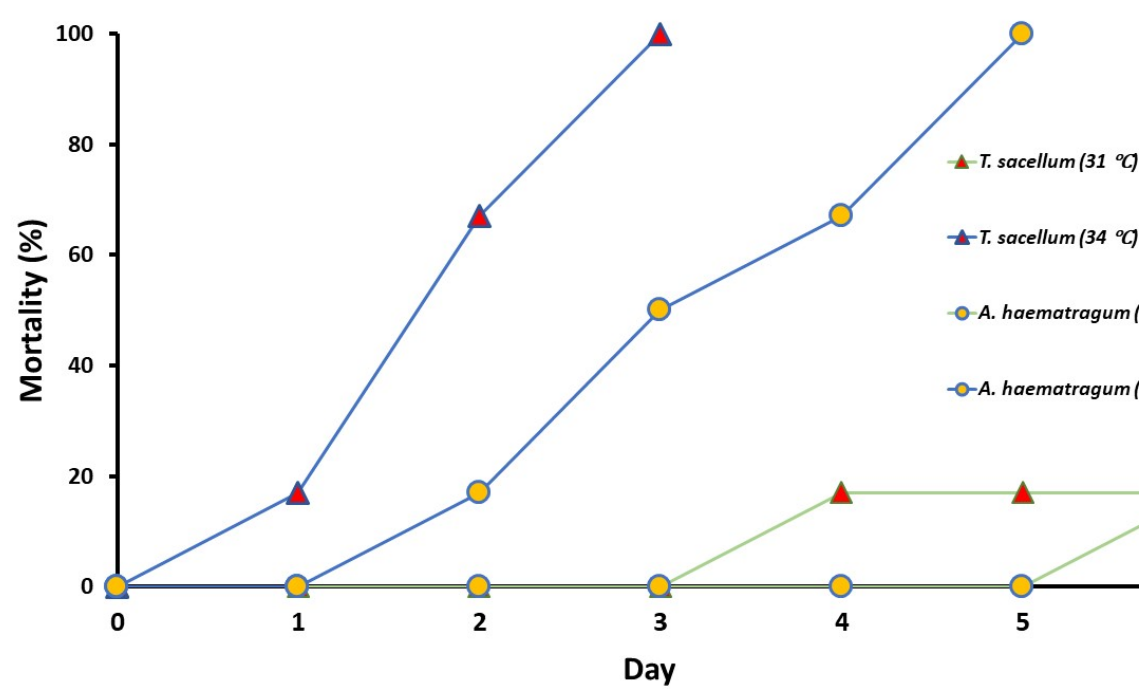


This is a final draft of the submitted paper. Please refer to the published version of this paper: Hemraj, D.A., Posnett, N.C., Minuti, J.J., Firth, L.B. and Russell, B.D., 2020. Survived but not safe: Marine heatwave hinders metabolism in two gastropod survivors. Marine Environmental Research, p.105117 https://doi.org/10.1016/j.marenvres.2020.105117

Figure 3

570

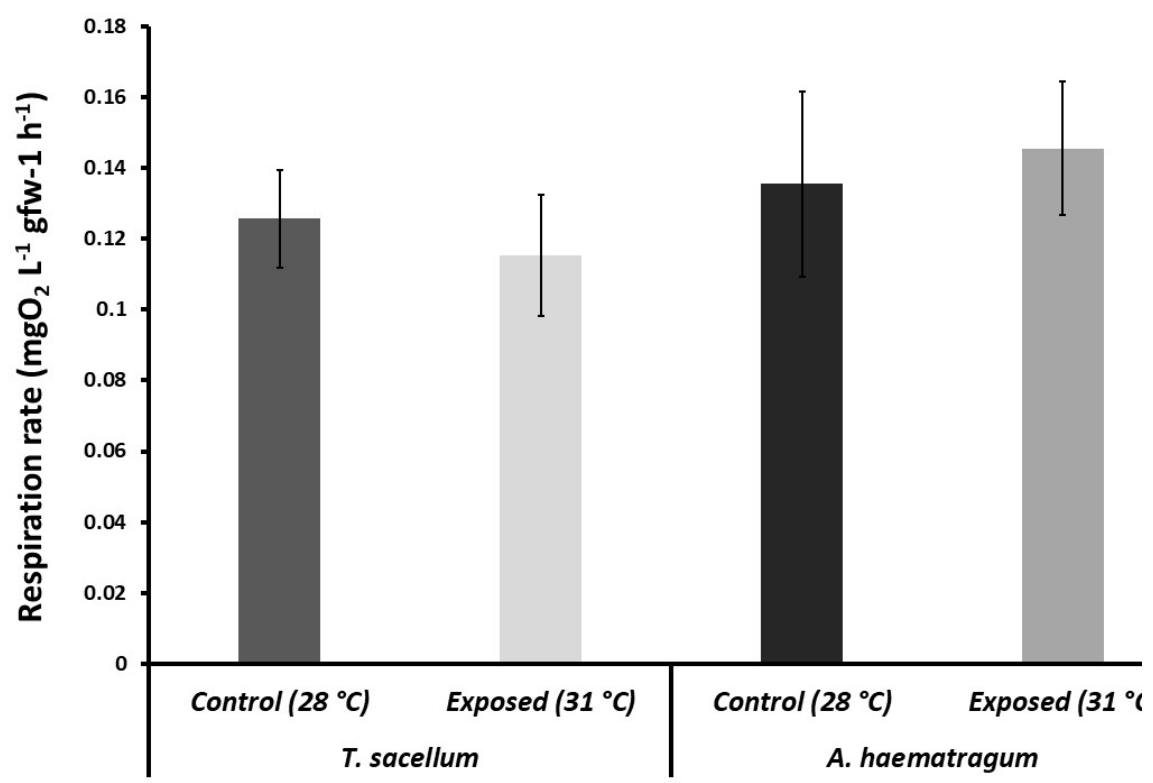


This is a final draft of the submitted paper. Please refer to the published version of this paper: Hemraj, D.A., Posnett, N.C., Minuti, J.J., Firth, L.B. and Russell, B.D., 2020. Survived but not safe: Marine heatwave hinders metabolism in two gastropod survivors. Marine Environmental Research, p.105117 https://doi.org/10.1016/j.marenvres.2020.105117

Figure 4

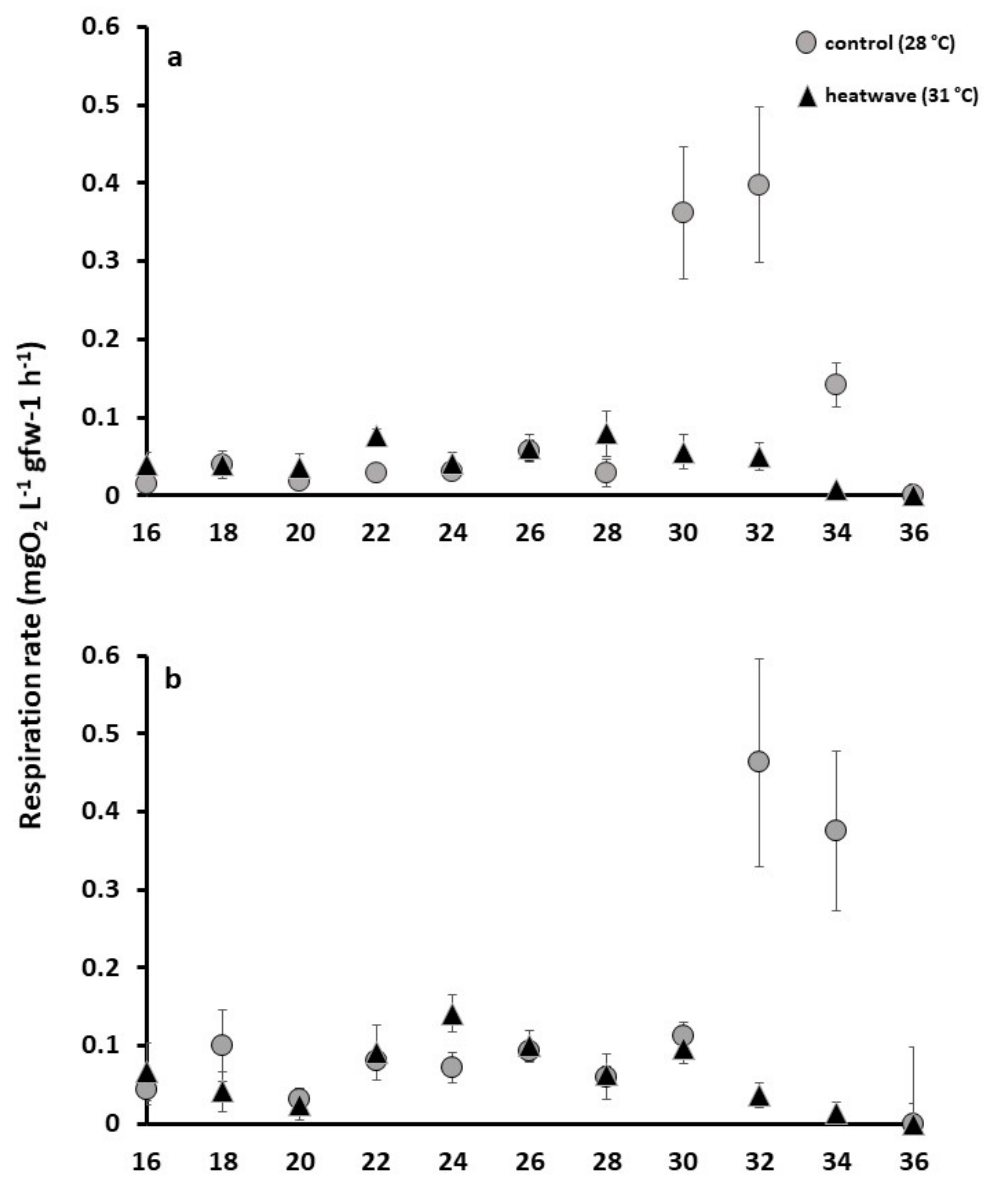

Temperature $\left({ }^{\circ} \mathrm{C}\right)$ 